\title{
SUPRAGLOTTIC AIRWAY DEVICES - A CONCEIT OR THE FUTURE OF AIRWAY MANAGEMENT?
}

\author{
Togay Evrin ${ }^{1}$, Mikolaj Rusin², Dawid Kacprzyk², Katarzyna Wieczorek², Klaudia Kulak², Marek Malysz² \\ ${ }^{1}$ Department of Emergency Medicine, UFuK University Medical Faculty, Ankara, Turkey \\ ${ }^{2}$ Lazarski University, Warsaw, Poland
}

Disaster Emerg Med J 2018; 3(3): 106-107

\section{Dear Sir,}

With great interest we read an article by Frass et al. entitled "Securing the airway patency by firefighters with the use of CombiTube. A pilot data" [1]. In this study, the authors present the effectiveness of airway management with the use of CombiTube by firefighters. According to numerous studies, the learning curve of supraglottic ventilation devices is significantly shorter than that of direct laryngoscopy [2, 3]. The history of supraglottic airway devices (SADs) dates back to the early 1980s. Since then, many types of these devices have appeared on the medical market and have undergone various modifications, an example of which is the fact that we can now purchase the third generation of SADs (Fig. 1). The initial devices, as was the case with the standard laryngeal mask (LMA), were composed of a ventilation channel and a sealing mask, however, the latest family of devices was additionally equipped with channels allowing the introduction of a catheter and decompression of the stomach from excess air or gastric contents.

Over the last decades, these devices have been used not only in emergency medicine, but also to protect the airway during short surgical procedures [4].

An update of the American Heart Association (AHA) resuscitation guidelines as well as the European Resuscitation Council (ERC) guidelines indicated supraglottic airway devices as a method of airway management during cardiopulmonary resuscitation. If the device is introduced into the airways, it is necessary to verify its correct position and airway protection, followed by auscultating upper abdomen, while chest compressions are being carried out.

This procedure is designed to prevent air leaks in the event of increased chest pressure - as is the case with chest compressions. If the person auscultating the upper abdomen does not hear murmurs suggesting air leaks, asynchronous cardiopulmonary resuscitation is permitted [3]. As indicated by numerous studies supraglottic airway devices can be used with high efficiency after a short training, so that they can be used, among others, by the firefighters mentioned by Frass et al. or nurses [1]. This makes it possible to protect the airway while performing an uninterrupted chest compression, which minimizes the length of the break during which the chest is not compressed. An additional aspect of using supraglottic airway devices is the possibility of using them in cases where access to the airways is limited, which precludes endotracheal intubation, as is often the case with patients trapped in a vehicle [5-7]. Therefore, it can be assumed that SADs are universal methods of airway protection, providing an important alternative for personnel without adequate experience in endotracheal intubation.

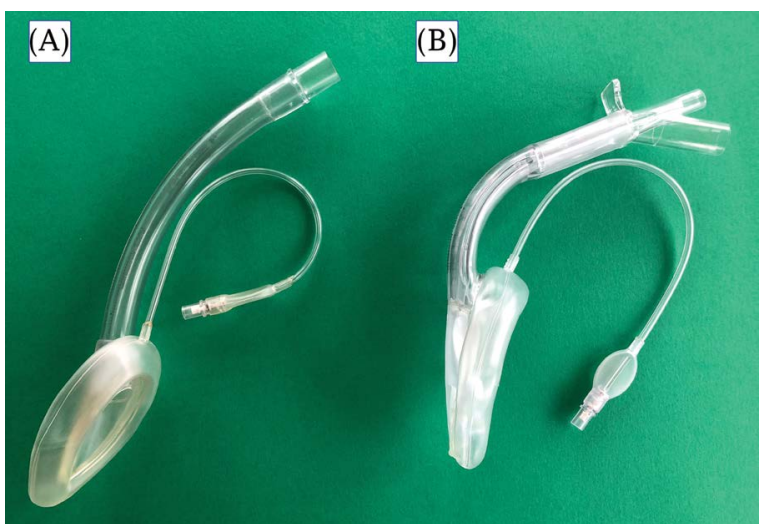

FIGURE 1. Laryngeal mask airway: A) 1-st generation LMA Unique (Laryngeal Mask Company Limited); B) 3-rd generation LMA Supreme (Teleflex) 


\section{REFERENCES}

1. Frass $M$, Robak 0 , Smereka J, et al. Securing the airway patency by firefighters with the use of CombiTube. A pilot data. Disaster Emerg Med J. 2018; 3(2): 46-50, doi: 10.5603/demj.2018.0011.

2. Sorbello M, Petrini F. Supraglottic Airway Devices: the Search for the Best Insertion Technique or the Time to Change Our Point of View? Turk J Anaesthesiol Reanim. 2017; 45(2): 76-82, doi: 10.5152/ TJAR.2017.67764, indexed in Pubmed: 28439437.

3. Sip M, Dabrowska A, Prucnal $K$, et al. Supraglottic devices — future or everyday life? Disaster Emerg Med J 2017;2(2):74-83. Disaster Emerg Med J. 2017; 2(2): 74-83, doi: 10.5603/DEMJ.2017.0015.

4. Robak O, Vaida S, Somri M, et al. Inter-center comparison of EasyTube and endotracheal tube during general anesthesia in minor elective surgery. PLoS One. 2017; 12(6): e0178756, doi: 10.1371/journal. pone.0178756, indexed in Pubmed: 28575056.
5. Szarpak Ł, Truszewski Z, Smereka J, et al. Are paramedics able to perform endotracheal intubation with access to the patient through the back seat of the car? Randomized crossover manikin study. Am J Emerg Med. 2016; 34(6): 1161-1163, doi: 10.1016/j.ajem.2016.02.062, indexed in Pubmed: 27079500.

6. Madziala A, Galazkowski R, Kaminska H, et al. Comparison of the airway access skills of medical students in cardiopulmonary resuscitation simulation: a randomized crossover study. Post N Med . 2018; XXXI(1): 42-47, doi: 10.25121/PNM.2018.31.1.42.

7. Madziala A, Evrin T, Wieczorek W, et al. et al.. Can the faceto-face intubation technique be used during cardiopulmonary resuscitation? A prospective, randomized, crossover manikin trial. Disaster Emerg Med J. 2017; 2(4): 145-149, doi: 10.5603/ DEMJ.2017.0033. 